\title{
Dynamics of Interregional Differentiation in Russian Regions Based on the Level of Development of Information and Communication Technologies
}

\author{
Sergey Baranov ${ }^{1}$ \\ Tatiana Skufina ${ }^{1}$ \\ Vera Samarina ${ }^{2}$ \\ Taisiya Shatalova ${ }^{1}$ \\ 1/nstitute of Economic Problems of the Kola Science Centre of the Russian Academy of Sciences, Russia \\ 2Staryy Oskol Technological Institute, branch of National Research Technological University "MISIS", Russia
}

\author{
Doi:10.5901/mjss.2015.v6n6s2p384
}

\begin{abstract}
The purpose of this study is identifying criteria and evaluation of interregional differentiation of information and communication space of Russia. The analysis of modern research and publications on the subject of the study of differentiation of space by the level of development of information and communication technologies was made. Demonstrated the specifics of different crosscountry differentiation, it is established that In contrast to the estimation of situation of cross-country differentiation, mark of positive tendency in development of interregional differentiation becomes convergence of regional information and communication technologies indicators, as well as unidirectional character of changes in regions. Multiple methods of estimating interregional differentiation are narrowed down to two basic approaches and to established their strength and weaknesses. We suggest measuring interregional differentiation of information and communication space in Russia by using both approaches. The main tendencies in specialty of development in differentiation of Russian Federation based on the indicators that characterize the information and communication component of regional development are shown. Quantitative estimations that characterize the level of informatization of Russian regions are built. It is defined that interregional differentiation of information and communication space is mainly high based on most of the estimate indicators. Established tendency of reduction in interregional differentiation on the criteria of informatization indicates that there is a positive territorial socio-economic transformation. It is determined that high level of development of information and communication technologies is typical for cities of federal importance and mining regions. Low and medium levels of informatization is typical for regions of different economic specialization, including those regions that are positioned as innovative regions.
\end{abstract}

Keywords: information and communication technologies, interregional differentiation, Russian regions, econometric analysis.

\section{Introduction}

An obvious difficulty of the problem resolution, regarding a contradiction between the extracting character of Russian economy and organization of economically modern and innovative model, generates not only scientific significance, but also a public demand for research aimed at solving specific problems of innovative movement that take into consideration real factors of economic development and spatial peculiarities of Russia. Among such studies the most important works are those aiming on estimating the perspectives for direction of development in information and communication technologies including specifics of space and economy. A significant direction of such research is focused on solving the problem of studying interregional dynamics of information and communication space in Russian regions. This significance is determined by the necessity of diagnosing situations with the goal to optimize management processes of informatization.

\subsection{Aims and objectives of the study}

The purpose of this study is identifying criteria and evaluation of interregional differentiation of information and communication space of Russia., including identifying specifics, level and tendencies of development of this phenomenon based on indicators that characterize informatization in regions of Russia.

Goals of the research: 1) identify factors of inter-country and interregional differentiation on the level of 
informatization and communication technologies; 2) consider the strength and weaknesses of the main methodological approaches to the quantitative estimation of interregional differentiation; 3) establish tendencies of interregional differentiation's development based on the complex of indicators reflecting the processes of informatization; 4) built ratings of Russian regions on the level of informational development.

\section{Analysis of Recent Studies and Publications}

There is lot of research dedicated to studying differentiation of space on the level of development of information and communication technologies. This is due to the fact that these technologies are the key factors of modern economy, and the processes of informatization are the main system of integration of these technologies into public life with the aim of not only producing new properties for organizing economic relations, but also modifying all of the aspects of public relations in general. This is evidenced by numerous theoretical and applied research about questions of information competence of the population (Tihomirova and Kocherga, 2012); estimation of qualitative changes of society through communication development (Archibugi and Coco, 2004; Babaeva, 2012; Baranov and Skufina, 2014 and Korres et al., 2014); estimation of influence of informatization on the character of economic relationship of countries and regions (Baranov and Skufina, 2014; Cardona et al., 2013; Majumdar et al., 2010; Skufina and Baranov, 2004). Analysis of these works allows stating that exactly the level of informatization development becomes a measure of quality of territories from the standpoint of both, economy and human capital development.

Based on this, the most important aspect for consideration of spatial non-uniformity of socio-economic development is informatization. This is why among scientific and applied research analytical papers are so widespread, which include analysis of cross-country comparisons based on the amount of people using internet in society level of development of information and communication technologies, indexes of web services. However, the author's research shows that in-country differentiation of informatization space may be more profound than the cross-country one (Baranov and Skufina, 2014;Skufina and Baranov, 2004). Scientific interest of considering exactly the interregional differentiation is defined by factors that define its specifics and development, which are qualitatively different from factors of cross-country spatial differentiation.

Cross-country differentiation is defined by global redistribution, systematically fixing the polarization of economic space. It is believed that absolute progress in development of information technologies in the peripheral countries is indicator of their successful and catching-up modern development (Archibugi and Coco, 2004 and Korres et al., 2014). However, in our opinion, quantitative convergence of ICT indicators should not be considered in developing countries with technologically developed, determinant of a positive tend of uneven social and economic development. This natural tendency characterizes only expansion of ICT market with redistribution of the main geopolitical and economic effects towards developed countries (Koblova, 2014 and Samarina, 2009).

From the management standpoint it is possible to state that factors of in-country (interregional) differentiation are fundamentally different. Interregional differentiation is the result of domestic policy and practices of territorial management. That is, this phenomenon is managed at the national level and even at the regional. Benchmarks of such management are to eliminate the disproportion of informatization space to a level that will not limit the implementation of regional socio-economic potential (Baranov and Skufina, 2014 and Samarina, 2009). In contrast to the estimation of situation of cross-country differentiation, mark of positive tendency in development of interregional differentiation becomes the convergence of regional ICT indicators, as well as unidirectional character of changes in regions.

Thus, the studies of interregional differentiation do not only present scientific interest, but also a practical one for managing territorial development of countries. So, in contrast to cross-country factors, regional factors' unevenness of informatization space allows to control the dynamics of processes. These factors have simple and unambiguous diagnostic criteria for the problem and estimation the impact of its regulation.

\subsection{Methodology and research methods}

This creates a methodological characteristic of the research - preferential use of quantitative estimates in diagnosis of the interregional differentiation phenomenon based on the criteria of informatization in Russian regional space. This approach allows obtaining accurate and statistically verified quantitative data about the specifics of the differentiation phenomena's development for each of the numerous and varied regions of Russia. For quantitative estimations there were used two methods. First - formation of the Lorenz curve and estimation of the Gini index analog for each of the indicators characterizing the informatization of Russian regions. Positive aspects: approved method allows estimating uneven distribution of studied feature (i.e. for each indicator, characterizing informatization) for regions of Russia. 
However, this method does not allow identifying which regions explain the size of the index most. That is why the research has to be completed with the second method - rated estimation of the level of informatization in Russian regions. This method allows on the basis of a set of indicators that characterize informatization of the region to determine the position (place) of each region among other Russian regions in terms of the level of informatization. More details about the research approach and interregional differentiation see in the next section of this paper.

\section{Key Findings of the Research}

There are a number of methodologies that are used for estimating interregional differentiation. However, all of this variety can be narrowed down to two main methodological approaches, which allow getting visual and well-interpreted results (Baranov and Skufina, 2014 and Samarina, 2009).

First approach - study about inequality in different components of any constituent of the regional system (in our case - ICT). Typically, methodologies are based on fundamental development of inequality estimation - analogs of the Lorenz curve and the Gini index. This approach allows to quantitatively characterizing the level of differentiation separately for every indicator chosen for the analysis of regional development. A positive feature is also the dimensionless analog of the Gini index, which allows tracking the dynamics of the process without the procedure of deflating. However, estimates of such regional differentiation do not allow evaluating what region (regional group) determines the value of the index. Also, it is not clear what is the exact position taken by a separate region (regional group) in the estimate.

Second approach - building complex (rating) estimates based on aggregate analysis of several regional parameters (in our case - characterizing development of ICT in a region). The essence of the method lies in the placing arrangements (or distance estimation) of the regions from the middle (or from some certain standard) in terms of separate indexes, and then - aggregation of the estimates into a single comprehensive estimate. External consistencies, ease of calculations, presentation of the results are all led to a widespread use of this approach in the scientific and practical studies. However, this approach only helps to define the position of a region with respect to a certain "regional average" level or in relation to other regions. That is, practically there is only ranking happening here which is not considered as a measure of differentiation. Nonetheless, this approach allows defining the exact region (region group) that determines the estimate of differentiation; divert it from the minimum value.

Thus, the second approach is going to be a natural complement to the first classical approach in order to estimate unevenness, based on calculating the Lorenz curve and the Gini index. For that reason we are offering to measure interregional differentiation of information and communication space in Russia using both approaches.

Estimates indicators: 1) number of personal computers (PC) per 100 people from the population; number of PC connected to the Internet per 100 people from the population; 3) acquisition cost of information technologies (IT) per capita; 4) acquisition cost of PC per capita; 5) cost of purchasing software per capita; 6) cost of services of a third party organization and specialists per capita (except telecommunication services and training); 7) number of registered mobile terminals per capita.

All of the regions of the Russian Federation participated in the calculation, except Ingushetia and Chechen Republic (due to lack of source data).

First approach - construction of the Lorenz curve and estimation of the analog of the Gini index for each of the evaluation parameters shown in table 1.

Please note most of the indicators of interregional differentiation are significant. Particularly high unevenness is demonstrated by the following indicators (normalized in per capita terms): cost of service (fluctuations in differentiation are between $73-55 \%)$, cost of training the personnel (68-54\%), cost of software (63-46\%), cost of purchasing PC (57$36 \%)$, cost of IT (54-42\%). No significant differentiation is common for the following indicators (normalized in per capita terms): number of PC with Internet connection (differentiation fluctuates between 28-13\%), number of mobile terminals (38-9\%), and number of PC (13-8\%).

It draws attention to the overall positive tendency - a reduction in interregional differentiation on all of the estimated indicators. This demonstrates not only the unification of information and communication conditions of the regions, but also becomes a highlighting trend of evening of socio-economic characteristics among Russian regions. 
Table 1 - Value of analog of the Gini index for regions of RF based on indicators, normalized in per capita terms in the region's population, calculated based on the data (Russian Statistics Committee, 2014)

\begin{tabular}{|c|c|c|c|c|c|c|c|c|}
\hline Year & $\begin{array}{l}\text { Number } \\
\text { of PC }\end{array}$ & $\begin{array}{l}\text { Number of PC } \\
\text { with Internet }\end{array}$ & $\begin{array}{l}\text { Cost } \\
\text { of IT }\end{array}$ & $\begin{array}{c}\text { Cost of } \\
\text { purchasing PC }\end{array}$ & $\begin{array}{l}\text { Cost of } \\
\text { software }\end{array}$ & $\begin{array}{l}\text { Cost of personnel } \\
\text { training }\end{array}$ & $\begin{array}{l}\text { Service } \\
\text { cost }\end{array}$ & $\begin{array}{c}\text { Number of } \\
\text { mobile } \\
\text { terminals }\end{array}$ \\
\hline 2003 & 0.13 & 0.28 & 0.54 & 0.57 & 0.63 & 0.63 & 0.73 & 0.38 \\
\hline 2004 & 0.14 & 0.27 & 0.45 & 0.46 & 0.61 & 0.54 & 0.58 & 0.30 \\
\hline 2005 & 0.12 & 0.23 & 0.47 & 0.44 & 0.49 & 0.55 & 0.61 & 0.22 \\
\hline 2006 & 0.11 & 0.21 & 0.46 & 0.45 & 0.51 & 0.60 & 0.59 & 0.14 \\
\hline 2007 & 0.10 & 0.20 & 0.44 & 0.40 & 0.51 & 0.54 & 0.57 & 0.12 \\
\hline 2008 & 0.09 & 0.18 & 0.42 & 0.39 & 0.46 & 0.55 & 0.57 & 0.12 \\
\hline 2009 & 0.08 & 0.15 & 0.44 & 0.38 & 0.51 & 0.74 & 0.58 & 0.11 \\
\hline 2010 & 0.07 & 0.16 & 0.44 & 0.37 & 0.52 & 0.68 & 0.56 & 0.09 \\
\hline 2011 & 0.09 & 0.14 & 0.42 & 0.37 & 0.50 & 0.65 & 0.56 & 0.10 \\
\hline 2012 & 0.08 & 0.14 & 0.43 & 0.37 & 0.51 & 0.66 & 0.55 & 0.09 \\
\hline 2013 & 0.09 & 0.13 & 0.43 & 0.36 & 0.50 & 0.64 & 0.55 & 0.09 \\
\hline
\end{tabular}

Second approach - complex estimation based on mythology often called "sum of places". This methodology is used often in target program documents for management the territorial development of Russia and scientific research.

The list of indicator estimates includes the same indicators as the once used for calculation of the Gini coefficient analog.

The first phase - for every indicator, included in the estimate, there is a determined rank (place) of every region starting from the top rank (ranked first) and finishes with the lowest (regions ranked last). In case of an indicator having the same place based on different estimates, the operation of local ranging is used considering the value of the parameter that was used as the main one for the calculation - number of personal computers (PC) per 100 people in the population.

Second phase is the operation of determining individual score for each region of RF; it is done with respect to the average Russian value, which is considered to be zero.

During the third phase, the sum of individual scores by region is summed up based on all of the indicators used in the evaluation. Then, the gained sum is divided by the overall quantity of used indicators. As the result, there is a summed score (integral), in our case it represents the level of informatization of Russian regions.

The goal of building the complex estimates is to evaluate which regions define deviation of differentiation from "the center of mass" influence. Table 2 and 3 shows ten "best" and ten "worse" regions, ranged based on data of year 2013, which respectively have the largest influence on the parameters of interregional differentiation of information and communication space.

Table 2 - Rank of Russian regions based on the level of ICT - "best" ten, calculated based on the data (Russian Statistics Committee, 2014)

\begin{tabular}{|clccccccccccc|}
\hline Place in 2013 Region & $\mathbf{2 0 0 3}$ & $\mathbf{2 0 0 4}$ & $\mathbf{2 0 0 5}$ & $\mathbf{2 0 0 6}$ & $\mathbf{2 0 0 7}$ & $\mathbf{2 0 0 8}$ & $\mathbf{2 0 0 9}$ & $\mathbf{2 0 1 0}$ & $\mathbf{2 0 1 1}$ & $\mathbf{2 0 1 2}$ & $\mathbf{2 0 1 3}$ \\
\hline 1 & City of Moscow & 21.0 & 25.9 & 27.1 & 27.4 & 28.4 & 27.6 & 25.0 & 25.3 & 26.3 & 26.8 & 25.9 \\
2 & City of St. Petersburg & 17.9 & 17.9 & 22.3 & 24.6 & 24.4 & 24.1 & 23.4 & 21.9 & 24.3 & 25.0 & 24.7 \\
3 & Magadan Oblast & -6.6 & -22.7 & -25.6 & 4.9 & 14.1 & 14.3 & 9.3 & 17.0 & 17.6 & 16.9 & 15.1 \\
4 & Tyumen Oblast & 11.7 & 19.3 & 22.0 & 21.0 & 21.9 & 18.9 & 14.4 & 16.6 & 13.1 & 14.2 & 13.8 \\
5 & Novosibirsk Oblast & 1.7 & 7.4 & 11.3 & 17.6 & 18.6 & 12.4 & 8.4 & 11.6 & 12.3 & 9.9 & 12.0 \\
6 & Khabarovsk Krai & 6.9 & 8.4 & 16.1 & 10.6 & 11.3 & 6.7 & 6.1 & 2.4 & 10.6 & 9.8 & 7.7 \\
7 & Novgorod Oblast & -13.7 & -14.4 & -19.1 & -11.0 & -8.9 & -5.1 & -5.4 & -13.4 & 10.3 & 7.1 & 7.6 \\
8 & Khanty-Mansi Autonomous Okrug & 3.3 & 22.0 & 23.0 & 22.0 & 23.0 & 16.7 & 8.0 & 9.9 & 9.0 & 9.0 & 7.5 \\
9 & Krasnoyarsk Krai & -0.3 & 0.3 & 8.3 & 1.1 & 13.0 & 11.6 & 14.3 & 14.4 & 10.3 & 7.0 & 7.0 \\
10 & Sakhalin Oblast & 4.3 & 0.6 & -0.3 & 16.0 & 18.4 & 17.7 & 16.6 & 12.6 & 7.4 & 0.4 & 6.1 \\
\hline
\end{tabular}


Table 3 - Rating of Russian regions based on the level of ICT - "worse" ten, calculated based on the data (Russian Statistics Committee, 2014)

\begin{tabular}{|c|c|c|}
\hline \multicolumn{2}{|c|}{ Place in 2013} & 20032004200520062007200820092010201120122013 \\
\hline 72 & Kursk Oblast & 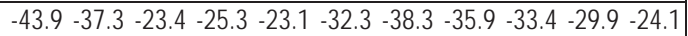 \\
\hline 73 & & 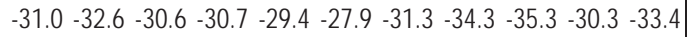 \\
\hline 74 & Tamb & $-34.6-34.3-38.9-36.6-33.6-32.4-3$ \\
\hline 75 & ay-Cherkessia Republic & $-36.0-41.9-2$ \\
\hline 76 & & $3-40.2$ \\
\hline 77 & & 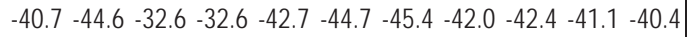 \\
\hline 78 & Brya & 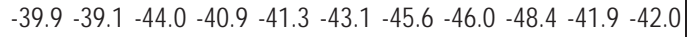 \\
\hline 79 & & 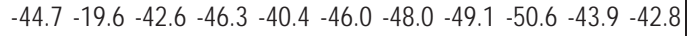 \\
\hline 80 & & 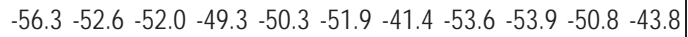 \\
\hline 81 & North Ossetia-Alania & 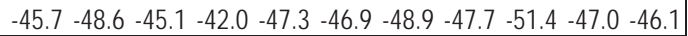 \\
\hline
\end{tabular}

The top ten are characterized by the best results of ICT development based on data from 2013 (considered to be members of extreme dynamic of the series) and those are regions with different specialization. Those are the cities of federal importance, which are Moscow and St. Petersburg; Oblast of Magadan, Tyumen, Novosibirsk, Novgorod, and Sakhalin; Krai of Khabarovsk and Krasnoyarsk; and Khanti-Mansi Autonomous Okrug. It is interesting to see the differences in the dynamics of a comprehensive assessment of the regions of this group, who are the most successful evenly.

Moscow, St. Petersburg, Tyumen and Novosibirsk Oblasts are always show consistently high level in different indicators. The rest of the regions demonstrate significant changes, mainly during the period between 2003 and 2004 and 2009 crises year. Note, the foundation of this group consists of the cities of federal importance, or regions with resources of economic importance for Russia, or mining regions of the Russian Federation.

The worse position in 2011 are consistently demonstrated by Kursk Oblast, Zabaykalsky Krai, Tambov Oblast, Karachay- Cherkessia Republic, Republic of Mari El, Republic of Adygea, Bryansk Oblast, Kabardino-Balkaria republic, republic of Dagestan, Republic of North Ossetia-Alania. Note, this group of "worse" regions consists of such places that are characterized by different economic specialization.

\section{Conclusion}

1. Interregional differentiation of information and communication space is mainly high based on most of the estimate indicators.

2. Established tendency of reduction in interregional differentiation on the criteria of informatization indicates that there is a positive territorial socio-economic transformation.

3. High level of development of ICT is typical for cities of federal importance and mining regions, which add their proceeds into the budget. Regions with different economic specializations demonstrate low level of informatization.

4. Gained results enabled us to determine further prospects of this research - find dependencies between the level of socio-economic development of Russian regions and the level of informatization.

\section{Acknowledgement}

Publication was prepared within the framework of projects supported by grants RFBR №13-06-00030, RHF №15-0200127.

\section{References}

Babaeva, L.V. (2012). Virtual samsara: transformation of reality model in conditions of information culture. Information society, 2, 44-51.

Baranov, S., \& Skufina, T. (2014). Information and communication technologies and economic development of Russian regions: search for dependencies and perspectives for directing regulations. Questions of statistics, 5, 41-53.

Koblova, U.A. (2014). Information limitations in information-network economy: new tendencies. Information society, 1, 17-24.

Russian Regions. Social and economic indicators (2014) / Official Internet - portal Ross stat / Available at ://www.gks.ru/bgd/regl//b14_ 14p/Main.htm

Samarina, V.P. (2009). Main methodological approaches to the assessment of unevenness of regional socio-economic development and 
identification of the problem of Russian regions. National interests: priorities and security, 12, 65-72.

Skufina, T., \& Baranov S. (2015) Measurement of informatization in regions of Russia. Modern problems of science and education, 1. http://www.science-education.ru/121-17823

Tihomirova, N.V., \& Kocherga S.A. (2012) Role and place of business education in context of developing the information society. Information society, 2, 26-36.

Archibugi, D. \& Coco A. (2004) A new indicator of technological capabilities for developed and developing countries (ArCo). World Development, 32 (4), 629-654.

Cardona, M., Kretschmer, T. \& Strobel, T. (2013) ICT and productivity: conclusions from the empirical literature. Information Economics and Policy, 25 (3), 109-125.

Korres G. (2011) Handbook of innovation Economics. New York, NY: Nova.

Majumdar, S., Carare, O. \& Chang H. (2010) Broadband adoption and firm productivity: evaluating the benefits of general-purpose technology. Industrial and Corporate Change, 19 (3), 641-674. 